\title{
Intraventricular hemorrhage in neonates born from 23 to 26 weeks of gestation: Retrospective analysis of risk factors
}

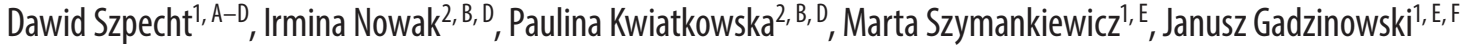 \\ ${ }^{1}$ Chair and Department of Neonatology, Poznan University of Medical Sciences, Poland \\ ${ }^{2}$ Student Scientific Group of Perinatal Medicine, Poznan University of Medical Sciences, Poland \\ A - research concept and design; $\mathrm{B}$ - collection and/or assembly of data; $\mathrm{C}$ - data analysis and interpretation; \\ $D$ - writing the article; $E$ - critical revision of the article; $F$ - final approval of article
}

Address for correspondence

Dawid Szpecht

E-mail: dawid.szpecht@poczta.fm

Funding sources

none declared

Conflict of interest

none declared

Received on February 1, 2016

Revised on July 12, 2016

Accepted on September 23,2016

\section{Abstract}

Background. The study aim was to determine the incidence and analyze risk factors of IVH stage 3 and 4 in infants born before 26 weeks of gestation.

Objectives. A retrospective analysis of 110 preterm babies (23-26 weeks of gestation) hospitalized from 2009 to 2014 at the Department of Neonatology of Poznan University of Medical Sciences was performed.

Material and methods. In the study group there were 29 (26.4\%) children in the $23^{\text {rd }}-24^{\text {th }}$ weeks of pregnancy and $81(73.6 \%)$ in the $25^{\text {th }}-26^{\text {th }}$ weeks of gestation.

Results. Among IVH stage 3 and 4 in neonates without prenatal steroids therapy, OR was 1.616 (1.059$2.456 ; p=0.022)$ for children born in the $23^{r^{\text {d }}}-24^{\text {th }}$ week of gestation and $1.677(1.001-2.809 ; p=0.047)$ for children born in the $25^{\text {th }}-26^{\text {th }}$ week of pregnancy. An analysis of various risk factors revealed the chance of the appearance IVH stage 3 and 4 among neonates born in the $23^{\text {th }}-24^{\text {th }}$ and $25^{\text {th }}-26^{\text {th }}$ week of gestation rising only among those children who were treated for hypotension with catecholamines (OR 2.031 (0.269-24.21), $p=0.033$ and OR $1.989(0.224-16.55), p=0.024)$.

Conclusions. The lower the gestational age, the more frequent the risk of IVH stage 3 and 4. The use of appropriate prophylaxis of perinatal patients (steroids in all pregnant women at risk of preterm birth, limiting the indications for the use of catecholamines for hypotension treatment) reduces the incidence of severe IVH.

Key words: risk factors, intraventricular hemorrhage, preterm neonates

DOI

10.17219/acem/65311

Copyright

Copyright by Author(s)

This is an article distributed under the terms of the

Creative Commons Attribution Non-Commercial License

(http://creativecommons.org/licenses/by-nc-nd/4.0/) 
Intraventricular hemorrhage (IVH) is the most common form of bleeding into the central nervous system in neonates and its occurrence is significantly increased in the group of very low birth weight (VLBW) preterm neonates born before the $32^{\text {nd }}$ week of gestation. The frequency of the IVH in preterm infants born between the $23^{\text {rd }}$ and $26^{\text {th }}$ week of gestation is $20-30 \% .^{1}$ The factors taken into account in the pathogenesis of IVH include impaired ability for autoregulation of cerebral blood flow with fluctuating cerebral blood flow (related to fluctuating arterial blood pressure), periodically with increased arterial blood pressure (e.g., due to hypercarbia, excess volume expansion) and increased cerebral venous pressure (e.g., with pneumothorax, asphyxial heart failure) and in combination with immature, fragile blood vessels within the germinal matrix tissue leading to hemorrhage into the ventricular system. ${ }^{2}$ About $90 \%$ cases of the IVH take place within the first 3 days of life and $20-40 \%$ of the IVH cases become more extended over the first week of life. In cases of grade 1 and 2, the clinical effects directly after the IVH and long-term effects are not noticed. In grade 3 or 4 , we may observe an abrupt deterioration in the clinical condition, consciousness disorders, seizures and certain neurological symptoms which include decreased spontaneous movement and muscle tone disturbances. In $60 \%$ of premature infants suffering from IVH stage 3 and 4, cognitive disabilities such as cerebral palsy and mental retardation incur. ${ }^{3}$

\section{Material and methods}

\section{Study population}

One hundred-ten neonates born between the $23^{\text {rd }}$ and $26^{\text {th }}$ week of gestation, admitted to the Neonatal Intensive Care Unit at the Department of Neonatology, Poznan University of Medical Sciences in the years 2009-2014, were analyzed. In the study group, there were 29 (26.4\%) infants born in the $23^{\text {rd }}-24^{\text {th }}$ week of gestation (group A) and 81 infants (73.6\%) born in the $25^{\text {th }}-26^{\text {th }}$ week of gestation (group B). The characteristics of the patients are shown in Table 1.

More mature newborns (older than 23-26 weeks of gestational age) were not included in this study. Also, neonates from multiple pregnancies, pregnancies in which one of the fetuses died, infants with chromosomal aberrations and TORCH infection were not taken into account. The retrospective analysis is the limitations of the study.

\section{Diagnosis of intraventricular hemorrhage}

The diagnostics of intraventricular hemorrhage were performed with neonatal cranial ultrasonography. The examination was carried out at least 3 times, according to the guidelines of the American Academy of Neurology in the $3^{\text {rd }}$ and $7^{\text {th }}$ day of life, and once more just before being discharged from the hospital. The stages of hemorrhages were categorized according to Papile IVH classification: grade 1 (hemorrhage to the periventricular germinal matrix), grade 2 (hemorrhage to the ventricular system without dilatation of the ventricles), grade 3 (hemorrhage to the ventricular system with dilatation of the ventricles) and grade 4 (intraparenchymal echodensity represents periventricular hemorrhagic infarction). ${ }^{4}$

\section{Risk factors}

The aim of the study was to examine the influence of the following factors: gender; gestational age (GA, weeks); birth weight (BW, grams); antenatal steroid therapy (AST, betamethasone $12 \mathrm{mg}$ intramuscularly every $24 \mathrm{~h}$ for 2 doses); small for gestational age (SGA, defined as birth weight under the $3^{\text {rd }}$ percentile); type of delivery (vaginal birth vs. cesarean section); delivery outside tertiary referral hospitals, birth asphyxia (defined as APGAR score less than 6 at $10 \mathrm{~min}$ and $\mathrm{pH}<7.0$ or blood base excess $(\mathrm{BE})<-15 \mathrm{mmoL} / \mathrm{L}$ in cord blood); intrauterine infection (defined as positive culture in a sterile environment originally accompanied by clinical symptoms); therapy in the first 7 days of life with crystalloids (bolus $10-15 \mathrm{~mL} / \mathrm{kg}$ ) and/or catecholamines of hypotension (defined as mean blood pressure below value corresponding to neonate's gestational age), treatment of the acidosis with $\mathrm{NaH}$ $\mathrm{CO} 3$ (when blood pH was below 7.2 and/or BE less than $-10 \mathrm{mmoL} / \mathrm{L}$ ); blood coagulation disorders (defined as prolonged prothrombin time (PT) below 65\% and/or increased International Normal Ratio (INR) more than 1.5 and/or prolonged activated partial thromboplastin time (APTT) more than $45 \mathrm{~s}$ in accordance with the reference values for the local laboratory); thrombocytopenia (defined as platelet count less than 100,000 per microliter of blood); type of respiratory support (invasive vs. noninvasive) on developing IVH.

\section{Statistical analysis}

A chi-square test with or without Yates' correction was applied to compare dichotomous variables, where appropriate. The odds ratio (OR) and 95\% confidence intervals (95\% CI) were calculated. Unconditional logistic regression analysis was used to adjust for the effect of confounders such as gender, GA, BW, AST, intrauterine hypotrophy, outborn patients, birth asphyxia, intrauterine infection, hypotension, acidosis, blood coagulation disorders, thrombocytopenia or respiratory ventilation (invasive vs. non-invasive). A p value below 0.05 was judged to be statistically significant.

The aforementioned statistical calculations were performed using CytelStudio v. 10.0, created January 16, 2013 (CytelStudio Software Corporation, Cambridge, USA), and STATISTICA v. 10, 2011 (Stat Soft, Inc.,Tulsa, USA). 
Table 1. Characteristics of patients

\begin{tabular}{|c|c|c|c|}
\hline Variables & $\begin{array}{l}\text { Group without IVH and with IVH } \\
\text { stage } 1 \text { and } 2(n=72 ; 65.5 \%)\end{array}$ & $\begin{array}{l}\text { Group with IVH stage } 4 \text { and } 4 \\
\qquad(n=38 ; 34.5 \%)\end{array}$ & $\mathrm{p}$-value \\
\hline $\begin{array}{l}\text { Gender } \\
\text { male } \\
\text { female }\end{array}$ & $\begin{array}{l}38(52.8 \%) \\
34(47.2 \%)\end{array}$ & $\begin{array}{l}22(57.9 \%) \\
16(42.1 \%)\end{array}$ & 0.099 \\
\hline $\begin{array}{l}\text { Gestational age (weeks) } \\
23-24 \\
25-26\end{array}$ & $\begin{array}{l}17(23.6 \%) \\
55(76.4 \%)\end{array}$ & $\begin{array}{l}12(31.6 \%) \\
26(68.4 \%)\end{array}$ & $<0.05$ \\
\hline $\begin{array}{l}\text { Birth weight (grams) } \\
<750 \\
750-1000 \\
>1000\end{array}$ & $\begin{array}{c}19(26.4 \%) \\
6(8.3 \%) \\
47(65.3 \%)\end{array}$ & $\begin{array}{l}12(31.6 \%) \\
16(42.1 \%) \\
10(26.3 \%)\end{array}$ & $<0.05$ \\
\hline $\begin{array}{l}\text { Apgar score (median and range) } \\
1^{\text {st }} \min \\
3^{\text {rd }} \min \\
5^{\text {th }} \min \\
10^{\text {th }} \text { min }\end{array}$ & $\begin{array}{l}3(1-7) \\
5(1-7) \\
6(2-8) \\
6.5(3-7)\end{array}$ & $\begin{array}{l}3(0-8) \\
5(1-8) \\
6(1-8) \\
7(2-9)\end{array}$ & $\begin{array}{l}0.833 \\
0.293 \\
0.412 \\
0.066\end{array}$ \\
\hline Deaths & $5(6.9 \%)$ & $8(21 \%)$ & $<0.05$ \\
\hline
\end{tabular}

Apgar score: Activity: 0 - limp; no movement; 1 - some flexion of arms and legs; 2 - active motion. Pulse (heart rate): 0 - no heart rate; 1 - less than 100 beats per minute; 2 - at least 100 beats per minute. Grimace: 0 - no reaction; 1 - grimacing only; 2 - grimacing and a cough, sneeze, or vigorous cry. Appearance: 0 - the baby's whole body is completely bluish-gray or pale; 1 - pink color in body with bluish hands or feet; 2 - pink color all over. Respiration (breathing): 0 - not breathing; 1 - weak cry, slow or irregular breathing; 2 - good, strong cry; normal rate and effort of breathing.

\section{Results}

The characteristics of the analyzed risk factors are shown in Table 2.

Statistical analysis demonstrated a significant difference in the frequency of appearance of IVH stage 1 and 2 and IVH stage 3 and 4 among neonates born in group $\mathrm{A}$ and group $B(p<0.05)$. OR for both stage 3 and 4 in the group of children born in group A was 4.863 (1.041$30.11 ; \mathrm{p}=0.043)$ and in group B was $3.494(0.914-19.65$; $\mathrm{p}=0.044)$.

Among neonates with no AST exposition with IVH stage 3 and 4, OR was $1.616(1.059-2.456 ; \mathrm{p}=0.022)$ for group A and 1.677 (1.001-2.809; $\mathrm{p}=0.047)$ for group $\mathrm{B}$. The analysis of various risk factors revealed that the chance of appearance of IVH stage 3 and 4 among neonates from group A and B rose only among those children who were treated for hypotension with catecholamines (OR 2.031 (0.269-24.21), p = 0.033 and OR 1.989 (0.22416.55), $\mathrm{p}=0.024)$. The remaining risk factors (asphyxia, treatment of acidosis with $\mathrm{NaHCO}_{3}$, parturition outside of the $3^{\text {rd }}$ stage of reference, mode of delivery and type of respiratory support) did not have any significant effect on the chance of appearance of IVH stage 3 and 4.

The chance of IVH stage 3 and 4 appearing among neonates from group A and B did not rise significantly among mothers who underwent steroid therapy and were treated for hypotension (OR 1.32 (0.755-2.309), $\mathrm{p}=0.323$ and OR $1.12(0.655-2.109), \mathrm{p}=0.412)$. Additional risk factors did not affect the probability of IVH stage 3 and 4 appearing: asphyxia (OR 1.544 (0.998-2.387), p = 0.054 and OR 1.561 (0.922-2.644), $\mathrm{p}=0.093)$, acidosis (OR 1.204 (0.645$2.248), \mathrm{p}=0.555$ and OR $1.07(0.52-2.031), \mathrm{p}=0.823)$, de- livery outside of $3^{\text {rd }}$ stage of reference (OR 1.205 (0.637$2.28), \mathrm{p}=0.056$ and $1.090(0.56-2.119), \mathrm{p}=0.797)$.

Thirteen of 110 (11.8\%) patients died. In group A, 6 of $29(20.7 \%)$ newborns died, and in group B, 7 of $81(8.6 \%)$ newborns did not survive. 3 of 12 (25\%) infants with diagnosed IVH stage 3 and 4 from group A and 5 of 26 (19.2\%) with diagnosed IVH stage 3 and 4 from group B died.

\section{Discussion}

The analysis of risk factors based on neonates born from the $23^{\text {rd }}$ to $26^{\text {th }}$ week of gestation in the Department of Neonatology, Poznan University of Medical Sciences, confirmed that hypotension and lack of AST are important risk factors of IVH.

Neonatal hypotension is defined as a mean blood pressure lower than the value of the child's gestational age. However the definition of hypotension in VLBW infants is controversial. The management of circulation and blood pressure in very preterm infants varies among neonatal intensive care units. In our unit, hypotension was defined as mean blood pressure below the value corresponding to the neonate's gestational age. 83 of 110 (75.45\%) neonates from our study were subjected to a catecholamine therapy, and the most frequently used form of treatment was administrating dopamine in combination with dobutamine.

The association between postnatal hypotension in VLBW infants and short- and long-term outcome is controversial. In our study group, treatment involving administrating catecholamines doubled the risk of appearance of IVH stage 3 and 4. Catecholamine therapy 
Table 2. Characteristics of risk factors

\begin{tabular}{|c|c|c|c|}
\hline Variables - risk factors & $\begin{array}{l}\text { Group without IVH and with IVH } \\
\text { stage I and II }(\mathrm{n}=72 ; 65.5 \%)\end{array}$ & $\begin{array}{l}\text { Group with IVH stage III and IV } \\
\qquad(\mathrm{n}=38 ; 34.5 \%)\end{array}$ & p-value \\
\hline $\begin{array}{l}\text { IUGR } \\
\text { yes } \\
\text { no }\end{array}$ & $\begin{array}{c}6(8.3 \%) \\
66(91.7 \%)\end{array}$ & $\begin{array}{c}2(5.3 \%) \\
36(94.7 \%)\end{array}$ & 0.555 \\
\hline $\begin{array}{l}\text { Prenatal steroids } \\
\text { yes } \\
\text { no or uncompleted }\end{array}$ & $\begin{array}{l}56(77.8 \%) \\
16(22.2 \%)\end{array}$ & $\begin{array}{l}14(36.8 \%) \\
24(63.2 \%)\end{array}$ & $<0.05$ \\
\hline $\begin{array}{l}\text { Mode of delivery } \\
\text { vaginal } \\
\text { cesarean section }\end{array}$ & $\begin{array}{l}40(55.6 \%) \\
32(44.4 \%)\end{array}$ & $\begin{array}{l}25(65.8 \%) \\
13(34.2 \%)\end{array}$ & 0.472 \\
\hline $\begin{array}{l}\text { Asphyxia } \\
\text { yes } \\
\text { no }\end{array}$ & $\begin{array}{l}35(48.6 \%) \\
37(51.4 \%)\end{array}$ & $\begin{array}{l}24(63.2 \%) \\
14(36.8 \%)\end{array}$ & 0.145 \\
\hline $\begin{array}{l}\text { Intrauterine infection } \\
\text { yes } \\
\text { no }\end{array}$ & $\begin{array}{l}52(72.2 \%) \\
20(27.8 \%)\end{array}$ & $\begin{array}{l}23(52.6 \%) \\
15(47.4 \%)\end{array}$ & 0.210 \\
\hline $\begin{array}{l}\text { Hypotension therapy } \\
\text { yes } \\
\text { no }\end{array}$ & $\begin{array}{l}52(72.2 \%) \\
20(27.8 \%)\end{array}$ & $\begin{array}{r}31(81.6 \%) \\
7(18.4 \%)\end{array}$ & 0.278 \\
\hline $\begin{array}{l}\text { Acidosis therapy } \\
\text { yes } \\
\text { no }\end{array}$ & $\begin{array}{l}65(90.3 \%) \\
7(9.7 \%)\end{array}$ & $\begin{array}{r}33(86.8 \%) \\
5(13.2 \%)\end{array}$ & 0.582 \\
\hline $\begin{array}{l}\text { Blood coagulation disorders and/or thrombocytopenia } \\
\text { yes } \\
\text { no }\end{array}$ & $\begin{array}{l}15(20.8 \%) \\
57(79.2 \%)\end{array}$ & $\begin{array}{l}14(36.8 \%) \\
24(63.2 \%)\end{array}$ & 0.069 \\
\hline $\begin{array}{l}\text { Respiratory ventilation } \\
\text { non-invasive } \\
\text { conventional }\end{array}$ & $\begin{array}{c}6(8.3 \%) \\
66(91.7 \%)\end{array}$ & $\begin{array}{l}0(0 \%) \\
38(100.0 \%)\end{array}$ & 0.067 \\
\hline $\begin{array}{l}\text { Third level hospital } \\
\text { outborn } \\
\text { inborn }\end{array}$ & $\begin{array}{l}10(13.9 \%) \\
62(86.1 \%)\end{array}$ & $\begin{array}{r}9(23.7 \%) \\
29(76.3 \%)\end{array}$ & 0.196 \\
\hline
\end{tabular}

turned out to have negative effects on both neonates born in the $23^{\text {rd }}-24^{\text {th }}$ week of gestation and neonates born in the $25^{\text {th }}-26^{\text {th }}$ week of gestation. The results of our study are compatible with other studies about IVH risk factors which include hypotension therapy as a potential cause of severe IVH. Rong et al. analyzed a group of 79 neonates diagnosed with IVH. ${ }^{5}$ The control group consisted of 153 neonates. In all three analyzed age groups ( $<30$ weeks, 30-34 weeks, 35-37 weeks), similarly to our findings, negative effects of hypotension treatment on IVH occurrence were reported.

Likewise, American post-hoc research of hypotension treatment of extremely preterm infants (23-25 weeks) showed negative effects of such therapy. ${ }^{6}$ Catecholamine therapy is listed there as a risk factor for IVH and periventricular leukomalacia. The examined infants were observed to have a lower survival rate and a growing tendency to develop later disorders, such as hearing impairment and cerebral palsy, than infants without hypotension or infants with untreated hypotension. The results of our research are important, because they advise caution while administrating catecholamine treatment to extremely preterm neonates. It is crucial to compare the possible benefits with potential risks.
The results of the research programs conducted are contradictory. Chinese (Rong et al.) and Israeli (Auerbach et al.) studies concerning the influence of hyperglycemia and other risk factors of IVH, confirmed that hypotension itself, due to hemodynamic distortion, is the risk factor for IVH occurring, even that of higher stages. ${ }^{5,7}$ However, other studies show that untreated hypotension does not worsen prognosis for the patient. American research of hypotension therapy shows that the later development of infants who didn't undergo hypotension treatment was comparable with the development of children who were not diagnosed with hypotension. ${ }^{6}$ On the other hand, children who underwent catecholamine therapy statistically fared less well.

In their research on untreated hypotension conducted on a group of 66 premature infants born in the $28^{\text {th }}$ week of gestation, Alderliesten et al. did not find any link between neurological disorders and hypotension itself (there was no confirmation of decreased regional cerebral oxygenation and lowered stage of neurological development). ${ }^{8}$ Some of the studies go as far as suggesting the pointlessness of anti-hypotension treatment - Batton et al. in their other research compared the blood pressure of 164 untreated premature infants - 135 treated with 
intravenous fluid therapy and 92 treated with dopamine. This research did not prove any significant difference in the rise of blood pressure within the first $24 \mathrm{~h}$ of life for both treated and untreated neonates. ${ }^{9}$

Faust et al. evaluated the lowest mean arterial blood pressure during the first $24 \mathrm{~h}$ of life (miniMAP24) in VLBW infants and its association with short-term outcome. The retrospective analysis of 4907 VLBW infants confirmed that in infants below 29 weeks of gestation, the lowest mean arterial blood pressure during the $24 \mathrm{~h}$ was 1-2 $\mathrm{mm} \mathrm{Hg}$ below the value of gestational age and hypotension defined as miniMAP24 lower than the median value of all patients of the same gestational age was associated with higher mortality and IVH rates. Moreover, infants treated with inotropes during the first $24 \mathrm{~h}$ of life had a higher risk for IVH. The rates of IVH in newborns with miniMAP24 in the lowest quartile for gestational age were higher in comparison to those with miniMAP24 $>25^{\text {th }}$ percentile. MiniMAP24 was a significant predictor for IVH in infants that were not treated with inotropes on the first day of life. ${ }^{10}$

It is difficult to establish the appropriate criteria of initiating catecholamine treatment. One of the most popular criteria is a fall of blood pressure $5 \mathrm{~mm} \mathrm{Hg}$ less than the correct level and the presence of at least 2 indicators of hypoperfusion, such as average blood pressure lowered by $3 \mathrm{~mm} \mathrm{Hg}$, lactate $>4 \mathrm{mmoL} / \mathrm{L}$ or capillary refill time $>4 \mathrm{~s} .{ }^{11}$ In their other research, Batton et al. initiated hypotension treatment on 203 neonates born between the $23^{\text {rd }}$ and $26^{\text {th }}$ week of gestation, based on 15 different definitions of hypotension. In all treated groups, a higher risk of IVH occurring and lower survival rate were observed. Independently from the moment of administration, catecholamines caused a higher risk of the occurrence of the aforementioned complications. ${ }^{12}$

It is also worth taking into consideration the introduction of therapies alternative to catecholamine therapy. Ibrahim et al. compared and analyzed the outcomes of 4 independent studies conducted on a group of 123 premature infants, concerning the introduction of steroidal therapy as an alternative to the use of dopamine as a firstline medication, and a treatment of hypotension resistant to catecholamine therapy. ${ }^{13}$ According to that research, hydrocortisone was as effective a first-line medication as dopamine. Additionally, compared to a placebo, hydrocortisone did not statistically affect the risk of IVH occurring and did not increased mortality rate, which probably makes it a safer alternative to catecholamines. Currently, the permissive hypotension in preterm infants should be taken into consideration. A numerical blood pressure value lower than gestational age should not be used as the only indicator for treating early-period hypotension in VLBW. Administrating hypotension treatment should be based on the clinical condition of patients. ${ }^{14}$ Hypotension therapy should be carefully thought out, keeping in mind the fact that there is increased risk of the adverse short- term and long-term outcome (neuro-developmental impairment). ${ }^{15,16}$

AST is administered to women in case of prediction of preterm delivery and aims to accelerate fetal lung maturation and therefore reduce the incidence and severity of respiratory distress syndrome (RDS). Moreover, a lot of studies agreeably show that it reduces overall neonatal mortality (RR 0.69; 95\% CI 0.58-0.81). It is also conducive to circulatory stability in preterm neonates, resulting in lower rates of cerebro-ventricular hemorrhage (RR 0.54; 95\% CI 0.43-0.69), necrotizing enterocolitis (RR 0.46 ; $95 \%$ CI $0.29-0.74)$, and systemic infections in the first 48 hours of life (RR 0.56; 95\% CI 0.38-0.85). ${ }^{17}$ In the analyzed population of newborns without AST, the risk of IVH stage 3 and 4 increased. In infants born in the $23^{\text {rd }}$ $24^{\text {th }}$ week of gestation, OR was 1.616 and in infants born in the $25^{\text {th }}-26^{\text {th }}$ week of gestation it was 1.677 . Our analysis has revealed that in both groups of neonates (those born in the $23^{\text {rd }}-24^{\text {th }}$ week of gestation and those born in the $25^{\text {th }}-26^{\text {th }}$ week of gestation), the lack or uncompleted AST is a risk factor of severe IVH. In 70 (63.6\%) cases, AST was performed. Severe IVH (stage 3 and 4) was confirmed in $24(63.2 \%)$ neonates without AST and in $14(36.8 \%)$ newborns exposed to AST. A 2006 metaanalysis of randomized trials of AST in women at risk of preterm birth provided strong evidence that IVH is significantly reduced when AST was given from the $26^{\text {th }}$ to $34^{\text {th }}$ week of gestation. ${ }^{17}$ AST administration before the $24^{\text {th }}$ week of gestation is still unclear. A 2016 meta-analysis of randomized trials of AST before the $24^{\text {th }}$ week of gestation did not demonstrate a reduction of severe IVH. ${ }^{18}$ A Japanese retrospective analysis of 11,607 infants born in the $22^{\text {nd }}$ to $33^{\text {rd }}$ week of gestation revealed that AST exposure was associated with a significant decrease in mortality of preterm infants born in the $22^{\text {nd }}$ to $23^{\text {rd }}$ week of gestation. Moreover, AST treatment was extremely effective at decreasing both IVH and severe IVH in preterm infants at the gestational age of 24 to 29 weeks, however not in infants born at $<24^{\text {th }}$ week of gestation. ${ }^{19}$ Carlo et al. $^{20}$ included 10,541 newborns with body weight between $401 \mathrm{~g}$ and $1000 \mathrm{~g}$ and who were born in the $22^{\text {nd }}$ to $25^{\text {th }}$ week of gestation at 23 academic perinatal centers in the United States. Infants were categorized as having been exposed to AST if their mother received 1 or more doses of dexamethasone or betamethasone, or not exposed if their mother did not receive AST. Of the 5691 infants born between 1993 and 2008 who survived to 18 to 22 months, 4924 (86.5\%) had neuro-developmental assessments performed by certified examiners who were unaware of exposure to antenatal corticosteroids. Death or neuro-developmental impairment at 18 to 22 months was significantly lower for infants who had been exposed to AST and were born in the $23^{\text {rd }}-25^{\text {th }}$ week of gestation, but not in those infants born in the $22^{\text {nd }}$ week of gestation. If the mothers had received AST, the following events occurred significantly less in infants born in the $23^{\text {rd }}, 24^{\text {th }}$ 
and $25^{\text {th }}$ week of gestation: death by 18 to 22 months, hospital death, death, IVH, PVL and necrotizing enterocolitis. For infants born in the $22^{\text {nd }}$ week of gestation, the only outcome that occurred significantly less was death and necrotizing enterocolitis. ${ }^{20}$

If we set together recommendations of AST and the results of the latest research, we can draw the conclusion that AST should be used. Is seems to be reasonable to lower the lower limit of AST administration and establish it at the $23^{\text {th }}$ week of pregnancy. The multiplicity of evidence on the benefits which arise from AST suggest that it is very important to respect the recommendations and administer AST routinely if only it is indicated.

It should be remembered that AST was performed in $63.6 \%$ of women in our study. In $24.1 \%$, contraindication for AST administration (chorioamnionitis) was diagnosed. In other cases, AST was not given due to urgent cesarean section (preterm placental abruption; 27.6\%) or a lack of adequate maternity care (48.3\%). It should be noted that AST was administered in $42.8 \%$ of infants born in the $23^{\text {rd }}$ week of gestation and it was performed beyond contemporary Polish recommendations.

Lack of or incomplete antenatal steroid therapy increases the probability of development of severe intraventricular hemorrhage. Hypotension therapy with catecholamines should be carefully thought out, keeping in mind the increased risk of intraventricular hemorrhage. The use of appropriate prophylaxis of perinatal complications (antenatal steroid therapy for women at risk of preterm birth, limiting the indications for the use of catecholamines for hypotension treatment) significantly reduces the incidence of intraventricular hemorrhage stage 3 and 4 . The significance of intraventricular hemorrhage creates a need to carry out periodical analysis, at the regional level, concerning its incidence, causes and effects to improve local treatment outcomes by identifying further courses of action.

\section{References}

1. Allen KA. Treatment of intraventricular hemorrhages in premature infants: Where is the evidence? Adv Neonatal Care. 2013;13:127-130.

2. Bassan $\mathrm{H}$. Intracranial hemorrhage in the preterm infant: Understanding it, preventing it. Clin Perinatol. 2009;36:737-762.

3. Payne AH, Hintz SR, Hibbs AM, et al. Neurodevelopmental outcomes of extremely low-gestational-age neonates with lowgrade periventricular-intraventricular hemorrhage. JAMA Pediatr. 2013;167:451-459.

4. Benders MJ, Kersbergen KJ, de Vries LS. Neuroimaging of white matter injury, intraventricular and cerebellar hemorrhage. Clin Perinatol. 2014;41:69-82.

5. Rong Z, Liu H, Xia S, Chang L. Risk and protective factors of intraventricular hemorrhage in preterm babies in Wuhan, China. Childs Nerv Syst. 2012;28:2077-2084.

6. Batton B, Zhu X, Fanaroff J, et al. Blood pressure, anti-hypotensive therapy, and neurodevelopment in extremely preterm infants. J Pediatr. 2009;154:351-357.

7. Auerbach A, Eventov-Friedman S, Arad I, et al. Long duration of hyperglycemia in the first 96 hours of life is associated with severe intraventricular hemorrhage in preterm infants. J Pediatr. 2013;163:388-393.

8. Alderliesten T, Lemmers PMA, van Haastert I, et al. Hypotension in preterm neonates: Low blood pressure alone does not affect neurodevelopmental outcome. J Pediatr. 2014;164(5):986-991.

9. Batton B, Li L, Newman NS, et al. Evolving blood pressure dynamics for extremely preterm infants. J Perinatol. 2014;34:301-305.

10. Faust $K$, Härtel $C$, Preuß $M$, et al. Short-term outcome of very-lowbirthweight infants with arterial hypotension in the first $24 \mathrm{~h}$ of life. Am J Perinatol. 2015;32(1):9-14.

11. Dempsey EM, Barrington KJ, Marlow N, et al. Management of hypotension in preterm infants (The HIP Trial): A randomised controlled trial of hypotension management in extremely low gestational age newborns. Neonatology. 2014;105:275-281.

12. Batton B, Li L, Newman NS, et al. Use of antihypotensive therapies in extremely preterm infants. Pediatrics. 2013;131:e1865-1873.

13. Ibrahim $H$, Sinha IP, Subhedar NV. Corticosteroids for treating hypotension in preterm infants. Cochrane Database Syst Rev. 2011;12:CD003662.

14. Azhan A, Wong FY. Challenges in understanding the impact of blood pressure management on cerebral oxygenation in the preterm brain. Front Physiol. 2012;3:471.

15. Batton B, Li L, Newman NS, et al. Early blood pressure, antihypotensive therapy and outcomes at 18-22 months' corrected age in extremely preterm infants. Arch Dis Child Fetal Neonatal Ed. 2016;101(3):201-216.

16. Logan JW, O'Shea TM, Allred EN, et al. Early postnatal hypotension and developmental delay at 24 months of age among extremely low gestational age newborns. Arch Dis Child Fetal Neonatal Ed. 2011;96(5):321-328.

17. Roberts D, Dalziel SR. Antenatal corticosteroids for accelerating fetal lung maturation for women at risk of preterm birth. Cochrane Database Syst Rev. 2006;3:CD004454.

18. Park CK, Isayama T, McDonald SD. Antenatal corticosteroid therapy before 24 weeks of gestation: A systematic review and meta-analysis. Obstet Gynecol. 2016;127(4):715-725.

19. Mori R, Kusuda S, Fujimura M. Antenatal corticosteroids promote survival of extremely preterm infants born at 22 to 23 weeks of gestation. J Pediatr. 2011;159:110-114.

20. Carlo WA, McDonald SA, Fanaroff AA, et al. Association of antenatal corticosteroids with mortality and neurodevelopmental outcomes among infants born at 22 to 25 weeks' gestation. JAMA. 2011;306:2348-2358. 